\title{
EFFECTS OF PARENTERAL IODOACETATE AND OTHER THIOL REAGENTS ON THE RABBIT RETINA* RELATION OF HISTOLOGICAL TO BIOCHEMICAL LESIONS
}

BY

\author{
J. P. NEWHOUSE AND D. R. LUCAS \\ Wernher Group for Research in Ophthalmological Genetics (Medical Research Council), \\ Royal College of Surgeons of England
}

NoELL (1951) showed that a single intravenous injection of $15-30 \mathrm{mg}$. of neutralized iodoacetic acid (IAA) per $\mathrm{kg}$. body weight rapidly extinguished the electroretinographic response to light of the rabbit retina. After two such injections of $20 \mathrm{mg}$. per $\mathrm{kg}$., given at an interval of 6-8 hrs, histological damage was noted: the visual cell nuclei became pyknotic and the sensory organelles deteriorated. Noell (1955) reported that glycolysis, a conspicuous function of the normal retina, was severely depressed shortly after the "irreversibly effective" second injection had been given. From his published figures, respiration also appeared to be impaired, but Noell regarded the fall in glycolysis as the primary cause of cell death.

Glycolysis and respiration both play an essential part in the metabolism of other nervous tissues. It is therefore surprising that the necrosis attributed primarily to glycolytic inhibition appeared to be confined to the retina. Some depression in carbohydrate metabolism seems to be characteristic of acute retinal damage, since it also accompanies lesions produced by $x$-radiation and by oxygen poisoning. Whether this type of biochemical defect is directly responsible for the subsequent development of necrosis or whether it is an incidental consequence of some other form of disorganization is unknown. One purpose of the present work was to establish the sequence of events that follow IAA injection, particularly the onset and early progress of the biochemical and histological lesions.

In its parenteral effects on the rabbit retina, IAA differs from other thiol reagents, none of which (except bromoacetate) is known to produce histological damage when injected at maximal tolerated dosage (Sorsby, Newhouse, and Lucas, 1957). That IAA possesses some unique capacity to interfere with retinal activity seems unlikely, for other thiol reagents have proved much more injurious to both the metabolism and structure of the isolated tissue when studied under standard conditions in vitro (Lucas and Newhouse, 1959). There is little reason to believe that IAA can cross bloodretinal barriers more readily than, for example, iodoacetamide or other potent thiol reagents.

* Received for publication December $2,1958$. 
The distinction is more probably due to circumstances, limited to parenteral work, which favour the effectiveness of IAA. First, IAA differs from most other thiol reagents in that its enzyme inhibitory effects are hardly reversed by the presence of thiol donors, such as glutathione (Barron and Singer, 1945). Removal of circulating IAA by this type of detoxication mechanism would also be unlikely. Secondly, IAA is better tolerated systemically than most other thiol reagents, many of which are too toxic for dosage to be raised indefinitely until a retinal lesion appears. In comparative studies of this type, the highest concentration of a drug to which the intact retina may be exposed is limited entirely by the ability of the animal to survive toxic side-effects, particularly on the medullary centres. At the lethal dosage, which varies widely with the agent used, respiratory failure terminates the experiment, whether or not the retina has been able to respond. Thus an intravenous dosage of $0.14 \mathrm{~m}$. mole IAA per $\mathrm{kg}$. is not lethal to the rabbit yet injures the retina; when other thiol reagents are given at this dosage, the animals soon die. To test the possibility that death supervenes before metabolic blockage can precipitate tissue damage, the retinal histology and biochemistry of such animals soon after injection have therefore been investigated.

\section{Methods}

Animals.-Adult Dutch rabbits (1.5-2 kg.), ophthalmoscopically normal at the time of treatment, were used. Each of 21 animals received a single intravenous dose of sodium iodoacetate (NaIA), $0 \cdot 14 \mathrm{~m}$. mole (equivalent to $26 \mathrm{mg}$. iodoacetic acid) per $\mathrm{kg}$. body weight. In order that both the short-term and the more protracted effects on the retina could be observed, these animals were killed at various intervals between $5 \mathrm{~min}$. and $24 \mathrm{hrs}$ after treatment. (Within a few days of injection, the disposal of necrotic debris and other secondary changes so alter the character of the tissue that its chemical behaviour cannot easily be interpreted.) Five other rabbits each received a single intravenous injection $(0.14 \mathrm{~m}$. mole per $\mathrm{kg}$.) of one of the following thiol reagents: ethyl iodoacetate ( 2 rabbits); sodium p-chloromercuribenzoate; phenacyl bromide; and 3-amino 4-hydroxyphenylarsine oxide hydrochloride. These animals were destroyed not longer than $1 \mathrm{hr}$ after injection.

Biochemical Studies.-The eyes were excised and opened in ice-cold oxygenated saline phosphate medium immediately after death. The retinae were dissected out and subdivided vertically. The pieces were then reassembled in portions (about $2 \mathrm{mg}$. dry weight) in which each segment was represented. One portion was always retained for histological fixation and the others were transferred to Warburg flasks (vol. $4 \mathrm{ml}$.), each containing medium $(1 \mathrm{ml}$.) and substrate. There was no evidence of substantial difference in activity between the ventral and dorsal segments.

Media.-It is impossible to reproduce in vitro the conditions that exist when the intact retina is exposed to parenteral IAA. Autologous plasma was used as 
incubating medium in some experiments with NaIA but, because the residual presence of this agent may depress retinal activity to a level even lower than that reached at the time of excision, saline media were employed more frequently.

Because the well-established Krebs-Ringer type media, buffered with either bicarbonate or phosphate, are not physiologically ideal, several authors have developed synthetic saline serum substitutes, in which a saline-bicarbonate mixture is supplemented by various organic acids (Krebs, 1950; Kornblueth, Yardeni-Yaron, and Wertheimer, 1953; Ames, 1956). Respiration and glucose utilization of tissues are thereby increased but, in our experience, the histological structure of the retina is less well maintained during incubation in these preparations than in the conventional saline media. Because we were interested in both the histological and the biochemical changes induced under the same conditions in the normal retina, the use of a saline phosphate (or bicarbonate) solution, as a suboptimal but relatively innocuous medium, was a necessary compromise.

Autologous plasma was used as medium in four NaIA experiments, as follows: venous blood ( $5 \mathrm{ml}$.) was withdrawn from a heparinized rabbit (anaesthetized with urethane); one eye was simultaneously excised and its retina rapidly dissected out in ice-cold saline. $5 \mathrm{~min}$. later an injection of NaIA was given. The blood obtained was centrifuged at $4^{\circ} \mathrm{C}$. and the resultant plasma was oxygenated. Some plasma was retained for measurement of lactate and reducing sugar while the rest was used to provide an incubation medium for portions of the control retina already dissected. $5 \mathrm{~min}$. after injection, the sequence was repeated: blood was withdrawn, the other eye was removed, and its retina was incubated in plasma obtained simultaneously.

The medium otherwise used was a saline-phosphate mixture, similar to that of

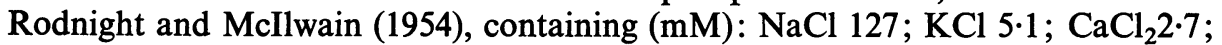
$\mathrm{MgSO}_{4} 1 \cdot 3 ; \mathrm{KH}_{2} \mathrm{PO}_{4} 1 \cdot 3 ; \mathrm{Na}_{2} \mathrm{HPO}_{4} 10 \cdot 0 ; \mathrm{HCl} \mathrm{2.0}$. Though the presence of calcium in physiological concentration does not permit maximal respiratory activity, this ion was always included in the medium.

Substrates.-Glucose $(10 \mathrm{mM})$ or sodium pyruvate $(20 \mathrm{mM})$ was always included in the saline-phosphate medium. No substrate was added at any stage in the plasma experiments; the reducing sugar concentration of plasma never fell below $4 \mathrm{mM}$.

Incubation.-Into the well of each flask was measured $0.1 \mathrm{ml}$. of either $\mathrm{KOH}$ ( 20 per cent. $\mathrm{w} / \mathrm{v})$ in aerobic studies or alkaline pyrogallol ( 5 per cent.) or phosphorus in anaerobic studies. The flasks were gassed for $7 \mathrm{~min}$. with the appropriate gas $\left(\mathrm{O}_{2}, \mathrm{O}_{2}-\mathrm{CO}_{2}\left(5\right.\right.$ per cent.), $\left.\mathrm{N}_{2}\right)$, and then incubated at $38^{\circ} \mathrm{C}$. for 70 min. in a Warburg respirometer bath. All manometric and photometric measurements of activity were made on duplicate portions of tissue, usually a piece from each eye, contained in separate respirometer assemblies, from which the mean activity was derived.

Later Treatment.-The flasks were later removed and cooled in ice. Samples of the medium, whether saline-phosphate or plasma, were taken for measurement in duplicate of lactic acid content by the method of Barker and Summerson (1941). The retinal tissue was pipetted out, using calcium-free saline-phosphate as washing fluid, centrifuged in 3-ml. conical centrifuge tubes, drained and dried at $110^{\circ} \mathrm{C}$. 
to constant weight. The rates of lactic acid formation and oxygen uptake were expressed as $\mu$ moles per g. dry weight of tissue per hour.

Histological Studies.-In sodium iodoacetate studies, whole eyes from ten rabbits and representative portions of the retinae from seven other rabbits used in biochemical work were removed at various times after injection, fixed in acid Zenker and embedded in ester wax as described by Chesterman and Leach (1956). Sections were stained by Mayer's haemalum and eosin. Eyes from the five rabbits injected with the other thiol reagents received similar histological treatment.

\section{HistologicAL}

\section{Results}

Sodium Iodoacetate.-No histological changes of any kind were seen at 5 min. or at $1 \mathrm{hr}$ after injection (Fig. 1).

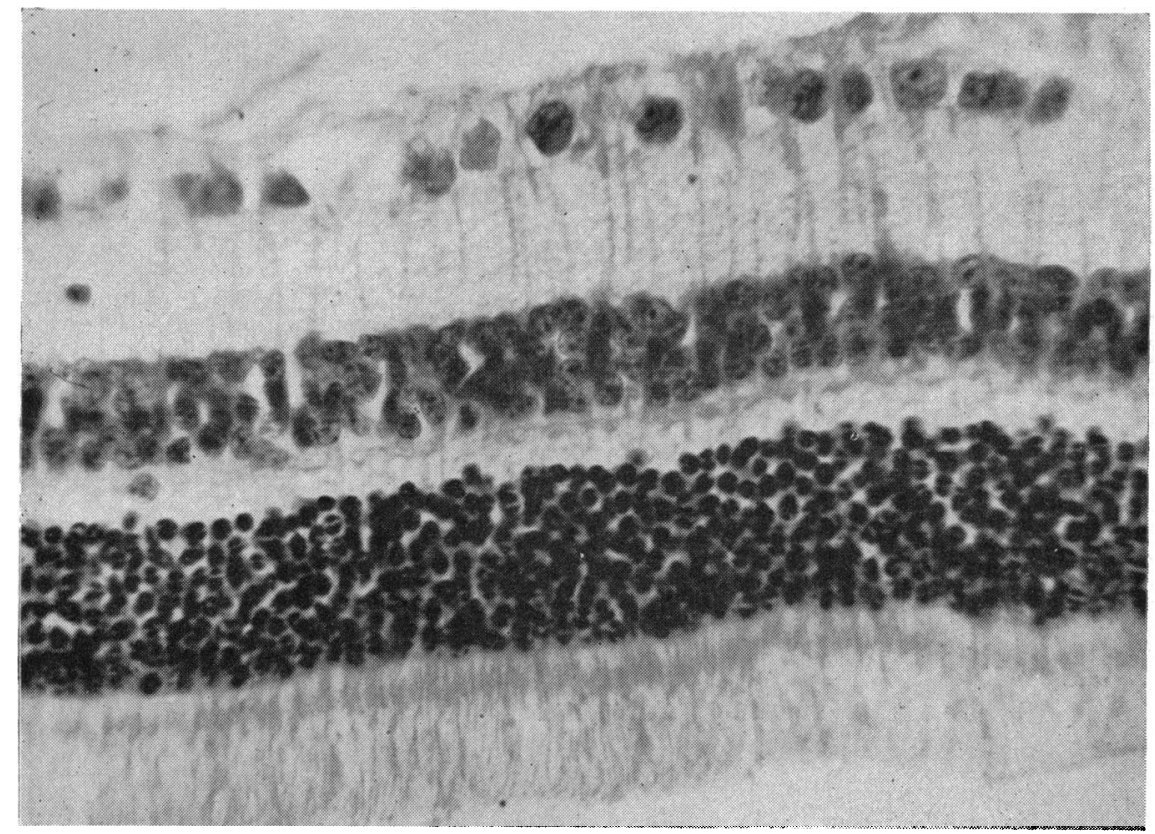

FIG. 1.-Area centralis $1 \mathrm{hr}$ after intravenous injection of NaIA (0.14 m. mole/kg.), showing no changes. Haematoxylin and eosin $\times 450$.

In the visual cell layer, nuclear pyknosis was visible at $4 \mathrm{hrs}$ and increased progressively thereafter (Figs $2-4$, overleaf); by 24 hrs, few nuclei were still intact and the rods themselves had become necrotic. In the inner layers also, nuclear pyknosis was always apparent from $4 \mathrm{hrs}$ onwards, though the proportion of nuclei affected varied considerably and was unrelated to time. The inner layers may even be the first affected, for in one rabbit (No. 741, Fig. 2) extensive pyknosis of the bipolar cells occurred at a time ( $4 \mathrm{hrs})$ when relatively few visual cells were pyknotic. Involvement of the pigment epithelium 


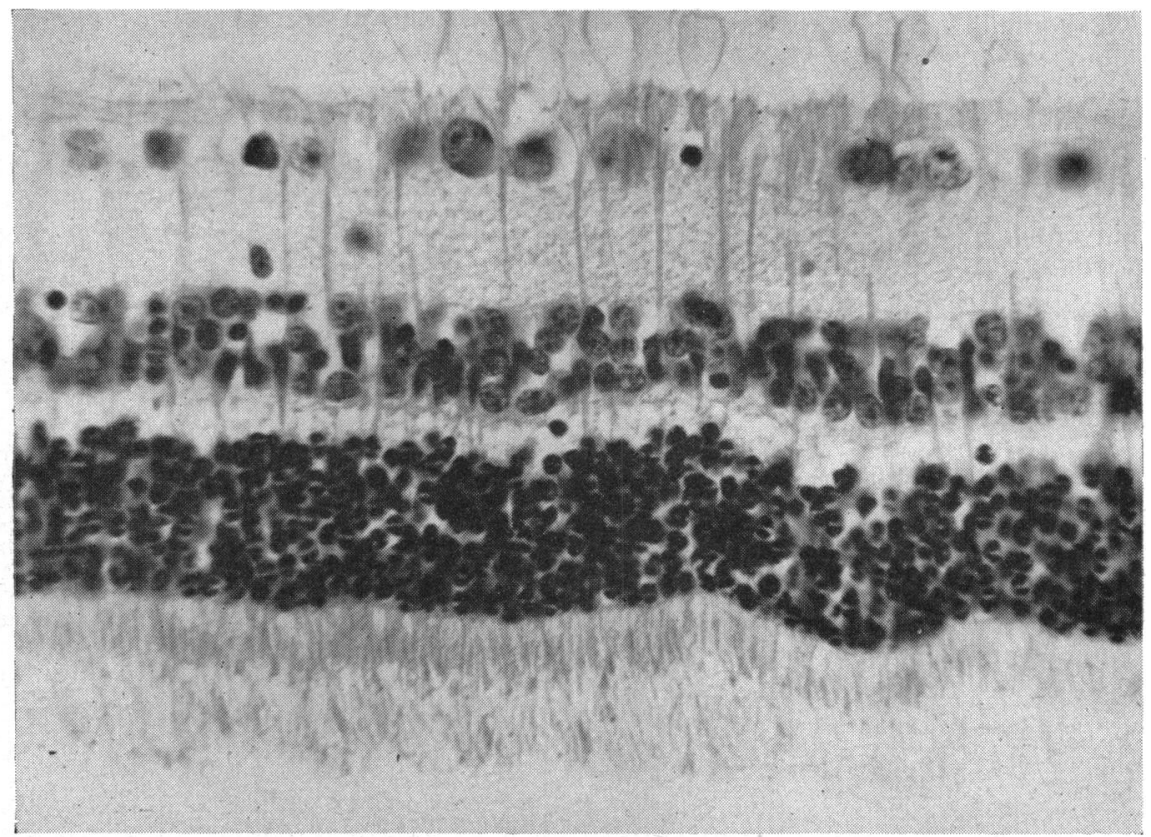

Fig. 2.-Area centralis $4 \mathrm{hrs}$ after intravenous injection of NaIA $(0.14 \mathrm{~m}$. mole $/ \mathrm{kg}$.), showing pyknotic nuclei in inner nuclear layer and two pyknotic ganglion cells. Haematoxylin and eosin $\times 450$.

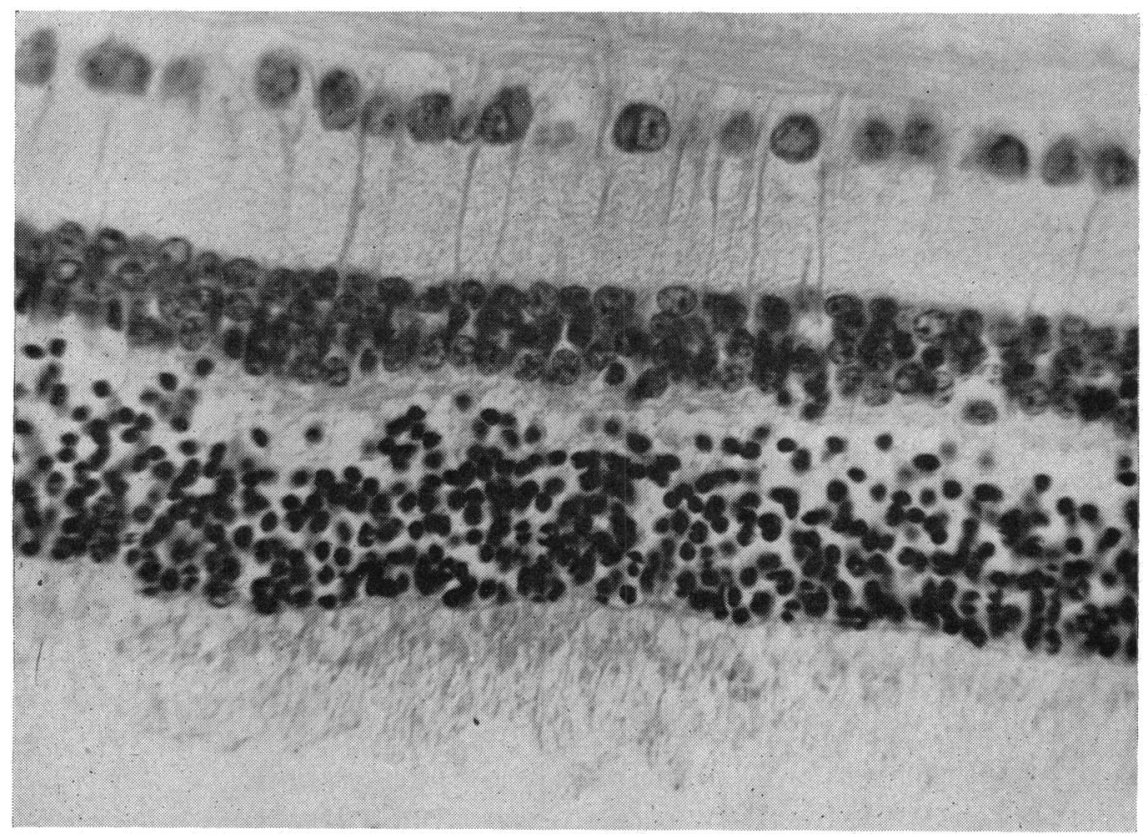

FIG. 3.-Area centralis $8 \mathrm{hrs}$ after intravenous injection of NaIA (0.14 m. mole/kg.), showing many pyknotic visual cells, but few affected cells in the inner layers. Haematoxylin and eosin $\times 450$. 


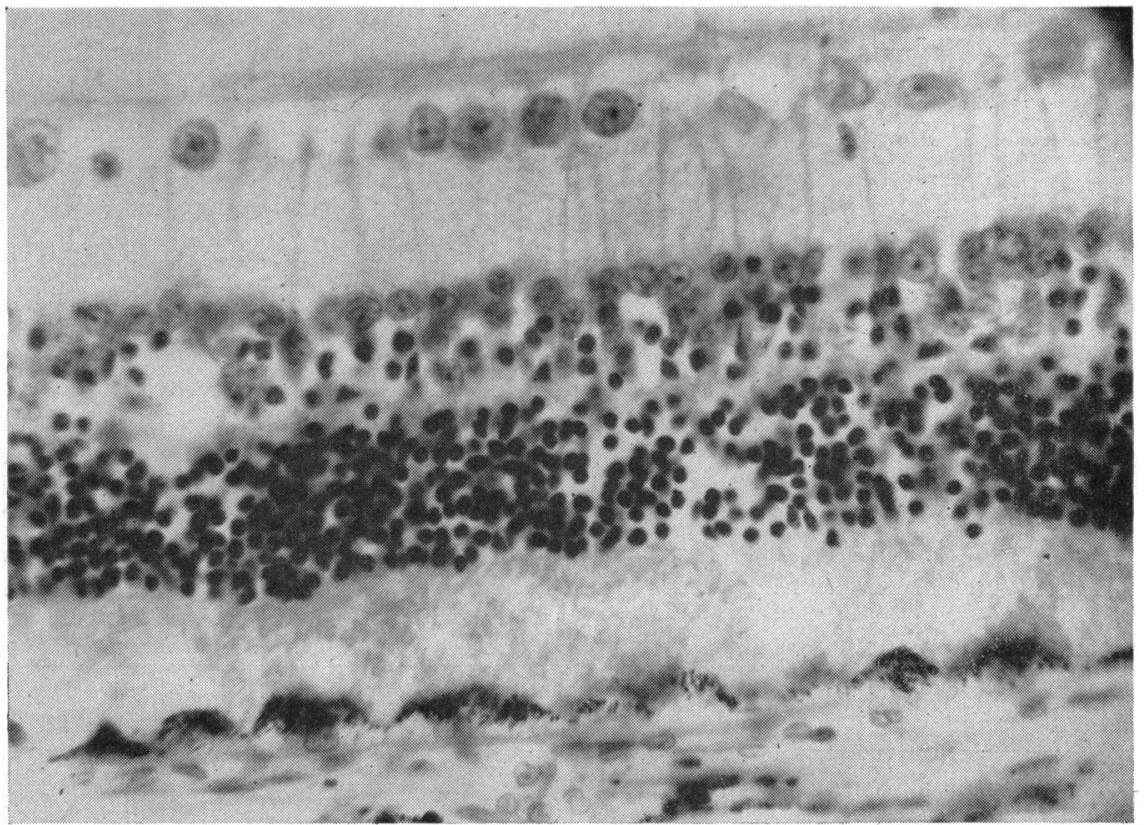

FIG. 4.-Area centralis $24 \mathrm{hrs}$ after intravenous injection of NaIA $(0 \cdot 14 \mathrm{~m}$. mole/kg.) showing extensive necrosis of the visual cell layer and many pyknotic bipolar cells (the latter appear more numerous than in Fig. 2, but inspection of the whole retinal field has shown that the difference is not great). Haematoxylin and eosin $\times 450$.

was harder to assess. Some swelling of the cells and scattering of the pigment granules was observed in two rabbits examined at $24 \mathrm{hrs}$, but such changes might not have been permanent. No earlier effect was seen.

The progressive nuclear changes in the various layers are shown in Table I.

TABLE I

EFFECT OF TIME AFTER NaIA INJECTION UPON NUCLEAR CHANGE

\begin{tabular}{c|c|c|c|c|c}
\hline $\begin{array}{c}\text { Time after } \\
\text { Injection } \\
\text { (hrs) }\end{array}$ & $\begin{array}{c}\text { Rabbit } \\
\text { No. }\end{array}$ & $\begin{array}{c}\text { Pigment } \\
\text { Epithelium }\end{array}$ & $\begin{array}{c}\text { Visual } \\
\text { Cells }\end{array}$ & $\begin{array}{c}\text { Bipolar } \\
\text { Cells }\end{array}$ & $\begin{array}{c}\text { Ganglion } \\
\text { Cells }\end{array}$ \\
\hline 1 & 738 (Fig. 1) & - & - & - & - \\
\hline 761 & - & - & - & - \\
\hline 4 & 741 (Fig. 2) & - & + & ++ & \pm \\
& 756 & - & \pm & \pm & - \\
\hline 8 & 758 & - & + & + & - \\
\hline 24 & 762 (Fig. 3) & - & + & + & + \\
\hline 76 & 740 (Fig. 4) & $?$ & +++ & + \\
& 775 & $?$ & +++ & + \\
\hline
\end{tabular}

- No change

\pm Occasional pyknotic nuclei $\left.\begin{array}{rl}+ & \text { Small } \\ + & \text { Moderate } \\ + & \text { Large }\end{array}\right\}$ proportion of pyknotic nuclei 
Other Thiol Reagents.-None of these substances caused perceptible damage to the retina during the first hour after injection.

\section{BIOCHEMICAL}

Two chemical functions of the retina of the experimental rabbit were studied simultaneously under varying conditions. These are defined and their levels of activity in the retinae of thirty normal adult rabbits are given in Table II.

TABLE II

OXYGEN UPTAKE AND LACTIC ACID FORMATION ( $\mu$ moles/g. dry wt. tissue/hr) IN VITRO OF RABBIT RETINAE REMOVED AT VARIOUS TIMES AFTER PARENTERAL ADMINISTRATION OF SODIUM IODOACETATE

Saline-phosphate medium $38^{\circ}$ C. $70 \mathrm{~min}$.

\begin{tabular}{|c|c|c|c|c|c|}
\hline \multirow{2}{*}{$\begin{array}{l}\text { Time after } \\
\text { Injection }\end{array}$} & \multirow{2}{*}{$\begin{array}{l}\text { Rabbit } \\
\text { No. }\end{array}$} & \multicolumn{2}{|c|}{ Oxygen Uptake } & \multicolumn{2}{|c|}{ Lactic Acid Formation } \\
\hline & & $\begin{array}{l}\text { I } \\
\mathrm{O}_{2} \text {-Glucose }\end{array}$ & $\begin{array}{c}\text { II } \\
\mathrm{O}_{2} \text {-Pyruvate }\end{array}$ & $\stackrel{\text { III }}{\mathrm{O}_{2} \text {-Glucose }}$ & $\begin{array}{c}\text { IV } \\
\mathrm{N}_{2} \text {-Glucose }\end{array}$ \\
\hline $5 \mathrm{~min}$. & $\begin{array}{l}573 \\
618\end{array}$ & $\begin{array}{l}221 \\
190\end{array}$ & $\begin{array}{l}268 \\
278\end{array}$ & $\begin{array}{l}769 \\
611\end{array}$ & $\begin{array}{r}1333 \\
572\end{array}$ \\
\hline & Mean & 205 & 273 & 690 & 952 \\
\hline $1 \mathrm{hr}$ & $\begin{array}{l}497 \\
586 \\
562 \\
593\end{array}$ & $\begin{array}{l}177 \\
152 \\
155 \\
193\end{array}$ & $\begin{array}{l}187 \\
183 \\
196 \\
109\end{array}$ & $\begin{array}{r}94 \\
446 \\
788 \\
776\end{array}$ & $\begin{array}{l}123 \\
782 \\
621 \\
877\end{array}$ \\
\hline & Mean & 169 & 169 & 526 & 601 \\
\hline $24 \mathrm{hrs}$ & 916 & 176 & 123 & 355 & 679 \\
\hline $\begin{array}{c}\text { Normal } \\
\text { Values } \\
\text { (30 Rabbits) }\end{array}$ & $\begin{array}{c}\text { Mean } \\
\text { Standard } \\
\text { Error } \\
\text { Range }\end{array}$ & $\begin{array}{c}388 \\
37 \cdot 3 \\
326-448\end{array}$ & $\begin{array}{c}409 \\
21 \cdot 5 \\
390-440\end{array}$ & $\begin{array}{c}870 \\
131 \cdot 1 \\
718-1101\end{array}$ & $\begin{array}{c}1121 \\
182 \cdot 2 \\
895-1318\end{array}$ \\
\hline
\end{tabular}

Sodium Iodoacetate.-Results are summarized in Table II. The retinae excised from two rabbits killed only $5 \mathrm{~min}$. after injection of NaIA showed some fall in oxygen uptake (I) and possibly in lactate formation (IV, No. 618). That the decline in respiration was largely independent of any prior effect on glycolysis was shown by its persistence when pyruvate (II) was used as substrate instead of glucose (I).

The retinae of four rabbits removed $1 \mathrm{hr}$ after injection displayed much less respiratory activity than before, while the corresponding values for anaerobic lactate formation (IV) showed, with one exception (No. 497), a comparable degree of depression. In the one animal killed at $24 \mathrm{hrs}$, lactate formation had not declined much more but respiration (II) was further depressed to a value little more than a third of the normal. 
When retinae were removed from four rabbits $5 \mathrm{~min}$. after iodoacetate injection and separately incubated aerobically for $1 \mathrm{hr}$ in iodoacetatecontaining plasma that had been withdrawn simultaneously from the same animals, a more pronounced depression of both respiration and lactate formation was observed than when a saline medium was used, as above; this was presumably due to prolonged exposure of the tissue in vitro to iodoacetate at its initial plasma level. By comparison with appropriate controls (values for retinae of the same animals excised before injection), oxygen uptake was reduced by at least two-thirds (percentage depression values: $64,76,85,88$, mean 78 ) while aerobic lactate formation was reduced to a similar extent (percentage depression values: $73,88,86,89$, mean 84 ).

Other Thiol Reagents.-Four of the rabbits on which measurements of retinal activity were made were killed exactly $1 \mathrm{hr}$ after the administration of one of the thiol reagents mentioned. The fifth rabbit, which received phenacyl bromide, died $5 \mathrm{~min}$. after injection and was studied immediately afterwards.

None of the three animals that received phenacyl bromide, sodium p-chloromercuribenzoate, or aminohydroxyphenylarsine oxide gave values for retinal respiration or lactate formation that were outside the normal range. The two rabbits (Nos. 49, 51) that received ethyl iodoacetate gave normal values for lactate formation but respiration was somewhat low (for No. $49, \mathrm{I}=235, \mathrm{II}=289$; for No. $51, \mathrm{I}=296, \mathrm{II}=270$ ).

\section{Discussion}

The present studies will be considered under four headings:

\section{(1) Selective Toxicity of Iodoacetate for the Visual Cells}

Earlier authors (Noell, 1952, 1953a, 1953b; de Berardinis, 1953; Karli, 1954) regarded the partial disappearance of the inner layers as a secondary effect of NaIA. Thus Noell (1953) stated that, in the rabbit, dosages higher than are needed to destroy most of the visual cells, may induce secondary atrophy of the inner layers, which develops only after large portions of the pigment epithelium have disappeared and retinal gliosis has ensued. Tansley (1955-6) noted briefly that she had confirmed Noell's findings, but added that small doses of iodoacetate always affected the horizontal cells and their fibres before they affected the visual cells.

In terms of iodoacetic acid, the dosage used in the present work $(26 \mathrm{mg}$. per kg.) was little higher than that used by Noell $(20 \mathrm{mg}$. per $\mathrm{kg}$.) yet could produce within a few hours considerable necrosis, not only of the visual cells, but also of cells in the inner layers. Since the latter may be affected even when many of the visual cell nuclei still appear normal (Fig. 2), it is unlikely that the primary degenerative effect of NaIA is strictly selective for 
the visual cells, as hitherto believed. Iodoacetate seems to interfere simultaneously with vital activities of both inner and outer layers.

\section{(2) Depression of Glycolysis and Respiration}

That NaIA depresses retinal glycolysis in vivo has seemed probable since Chinn and Noell (1951) reported that doses of 25 to $300 \mathrm{mg}$. neutralized iodoacetic acid per $\mathrm{kg}$. body weight could reduce the lactic acid content of the rabbit retina, removed $5 \mathrm{~min}$. after injection, by 53 to 64 per cent. respectively of the control value.

According to the unpublished work of Noell and Pawell, referred to by Noell (1955), the aerobic glycolysis $\left(\mathrm{Q}_{\mathrm{G}}^{2}\right)$ of rabbit retina excised at various times after IAA injection ( $20 \mathrm{mg}$. per $\mathrm{kg}$.) and incubated in vitro, was reduced by 78 per cent. at 30 min., 55 per cent. at $4 \mathrm{hrs}$, and 41 per cent. at $24 \mathrm{hrs}$. Such depression of glycolytic function is greater than that reported here (Table II), but the experimental conditions were not identical. However, in both investigations, glycolysis does show some tendency to revive with the passage of time after injection. Oxygen uptake, on the contrary, shows no sign of recovery after its initial depression. In the present work, values fell progressively and the fall was not reversed in any experiment during incubation of the excised tissue in the saline medium, which contained only glucose or pyruvate but no IAA. Indeed, this slow irreversible impairment of respiratory function seems to be characteristic of NaIA toxicity; it is apparent also in Noell's figures, though he does not discuss its significance. Brain slices treated with NaIA show a similar picture of progressive respiratory depression (Fuhrman and Field, 1943).

In contrast to the sensitivity of the rabbit tissue, the intact rat retina seems to respond poorly. Kornblueth and Ben-Shlomo (1956), who studied rats that had received much larger doses $(0.26 \mathrm{~m}$. mole NaIA per $\mathrm{kg}$.) $2 \mathrm{hrs}$ before ocular excision, reported a depression of only 30 per cent. in the carbohydrate utilization of the incubated retina; the glucose utilization of the brain was unaffected. The difficulty the present authors have experienced in regularly inducing even a minimal lesion of the rat retina with intravenous NaIA is probably related to this lesser metabolic response in vivo, for, when the rat tissue is studied in vitro, it is no less sensitive to the inhibitory and destructive effects of added NaIA than is that of the rabbit (Lucas and Newhouse, 1959).

\section{(3) Mode of INHibitory Action of Iodoacetate}

The fact that interference with carbohydrate metabolism persists for several hours in the retina before histological signs of tissue damage become visible is of interest. To identify with certainty the precise mechanism responsible for this lethal change is no easy task with so versatile an inhibitor as iodoacetate. Noell's original hypothesis that it acts by exerting a simple selective 
blocking action upon visual cell glycolysis has been questioned by Dische $(1953,1956)$ and Wald (1955), and the present work does little to confirm Noell's view. That glycolysis is depressed very soon after injection is certainly true. This effect may be responsible for the rapid extinction of the ERG response and the early appearance of pyknosis in the bipolar cells which lie in contact with the principal centre of lactic dehydrogenase activity (and presumably of glycolysis), the outer fibre layer. But in the visual cells such activity is relatively small, while that of the IAA-sensitive enzymes, malic and succinic dehydrogenases, is very high. The toxic effects of NaIA upon the retina are clearly not specific for a particular type of cell and there is no reason to expect them to be limited to a particular metabolic function, such as glycolysis, either ( $c f$. Barron and Singer, 1945). Inhibition of dehydrogenases associated with respiration could therefore be an alternative cause of cellular damage, though not, of course, the only one, since other means of depressing respiration (anoxia, cyanide) are by themselves not outstandingly destructive to the visual cell layer. The photochemical activity of the latter seems to be associated with high oxidative activity. Acute interference with respiration, at a time when the residual glycolytic function is also impaired, may therefore have serious consequences upon the function and, later, upon the integrity of the visual cell.

\section{(4) INFLUeNCE OF SySTEMic Factors}

The four other thiol reagents studied in this work exert greater inhibitory and destructive effects upon the isolated retina than does NaIA (Lucas and Newhouse, 1959). Thus sodium p-chloromercuribenzoate differs from NaIA in blocking rhodopsin synthesis (Wald and Brown, 1952). It rapidly inactivates the same thiol-dependent enzymes of carbohydrate metabolism (e.g. phosphoglyceraldehyde dehydrogenase) as does NaIA and several more besides. Though rather less effective against glycolysis, it is a more powerful inhibitor of respiration than is NaIA and, perhaps for this reason, it is more readily lethal when given parenterally. Yet, even when given at the same dosage, it fails to depress retinal glycolysis and respiration within an hour of injection, in the manner of NaIA. Similar remarks apply to the lacrimatory alkylating thiol reagents, phenacyl bromide, and ethyl iodoacetate, which, as enzyme poisons in vitro, are at least as active as NaIA in every respect (Mackworth, 1948), yet hardly seem to penetrate the retina of the intact animal in effective inhibitory quantity.

NaIA has several distinctive characteristics:

(a) It is a highly polar substance, the salt of a strong acid (contrast iodoacetamide and ethyl iodoacetate).

(b) It reacts relatively slowly with thiol groupings (contrast p-chloromercuribenzoate) and its inhibitory effects, $e . g$. on succinic dehydrogenase, are only slightly 
reversed in the presence of thiol donors such as glutathione (Barron and Singer, 1945). Its influence, both in plasma and in the retina, must therefore be difficult to counteract.

(c) It inhibits retinal respiration at dosages low enough not to cause systemic collapse.

It thus seems reasonable to suggest that the cytotoxic behaviour of this agent is not due simply to some specific affinity for visual cell metabolism, confined to iodoacetic acid among so many potent inhibitors, but that various extrinsic factors also play a part in the occurrence of the parenteral lesion.

\section{Summary}

(1) The retinae of adult rabbits were studied biochemically and histologically at various times between $5 \mathrm{~min}$. and $24 \mathrm{hrs}$ after intravenous injection of neutralized iodoacetic acid, NaIA $(0 \cdot 14 \mathrm{~m}$. mole per $\mathrm{kg}$.).

(2) Within $5 \mathrm{~min}$. of injection both respiration and glycolysis were independently depressed, particularly the former function, which did not recover within $24 \mathrm{hrs}$.

(3) By 4 hrs, nuclear pyknosis was visible, not only in the visual cells but also in the bipolar cells and increased progressively in both layers thereafter. In one rabbit, the bipolar cells appeared to be affected earlier than the visual cells.

(4) Four other thiol reagents were administered at the same dosage as NaIA but had no comparable effects upon the biochemistry or histology of the retina during the first hour following injection, though they are known to be more cytotoxic than NaIA to the retina in vitro.

(5) The distinctive properties of NaIA among thiol reagents are discussed, including high anti-glycolytic action, moderate anti-respiratory action, low systemic toxicity, polarity and slow reaction with thiol donors. It is suggested that the singular retinal lesion produced by NaIA may be due partly to simultaneous depression of both phases of carbohydrate metabolism in a heterogeneous tissue and partly to extrinsic factors, such as low lethality and capacity to penetrate the blood-retinal barrier.

We are indebted to Professor H. Mcllwain and Dr. O. A. Trowell for criticism of the present paper. Mrs. Doris Hatton, Miss June Hunter, Mrs. Toby Necci, and Miss Diana Tremain gave much valuable technical assistance. We are obliged to the Head of the Chemistry Section, Chemical Defence Experimental Establishment, Porton, for a gift of ethyl iodoacetate and to Messrs. Parke, Davis \& Co. Ltd. for the organic arsenical used in this study.

\section{REFERENCES}

Ames, A., III (1956). J. Neurophysiol., 19, 213.

BARKER, S. B., and Summerson, W. H. (1941). J. biol. Chem., 138, 535.

BARRON, E. S. G., and Singer, T. P. (1945). Ibid., 157, 221. 
Berardinis, E. de (1953). Rass. ital. Ottal., $22,345$.

Chesterman, W., and Leach, E. H. (1956). Quart. J. micro. Sci., 97, 593.

ChInN, H. I., and NoEll, W. K. (1951). U.S.A.F. School of Aviation Medicine, Randolph־Field, Texas. Project 211-23-011. Report No. 1.

Dische, Z. (1953). Amer. J. Ophthal., 36, June, Pt 2, p. 115. (1956). A.M.A. Arch. Ophthal., 56, 587.

Fuhrman, F. A., and Field, J., II (1943). J. cell. comp. Physiol., 21, 307.

KARLI, P. (1954). Ophthalmologica (Basel), 128, 137.

KORNBlueth, W., and Ben-Shlomo, E. (1956). A.M.A. Arch. Ophthal., 55, 813. , YARDENI-YARON, E., and WeRTHEIMER, E. (1953). Ibid., 50, 45.

KREBS, H. Ad (1950). Biochim. biophys. Acta, 4, 249.

LuCAS, D. R., and Newhouse, J. P. (1959). Brit. J. Ophthal., 43, 147.

MACKWORTH, J. F. (1948). Biochem. J., 42, 82.

NoEll, W. K. (1951). J. cell. comp. Physiol., 37, 283. (1952). Ibid., 40, 25. (1953a). Amer. J. Ophthal., 36, June, Pt 2, p. 103. (1953b). U.S.A.F. School of Aviation Medicine, Randolph Field, Texas. Project 21-1201-0004, Report No. 1. (1955). Amer. J. Ophthal., 40, Nov., Pt 2, p. 60.

Rodnight, R., and MCIlWAIN, H. (1954). Biochem. J., 57, 649.

Sorsby, A., Newhouse, J. P., and LuCAS, D. R. (1957). Brit. J. Ophthal., 41, 309.

Tansley, K. (1955-6). Inst. Ophthal. Ann. Rep., 8, Art. No. 22.

Wald, G. (1955). Amer. J. Ophthal., 40, Nov., Pt 2, p. 69. and Brown, P. K. (1952). J. gen. Physiol., 35, 797. 